\title{
A Study of Phonics Instruction: Teaching Phonics Dance to At-Risk Elementary Students to Improve Decoding Skills
}

Brittany Phipps

Cedarville University

Follow this and additional works at: http://digitalcommons.cedarville.edu/education theses

Part of the Education Commons

\section{Recommended Citation}

Phipps, Brittany, "A Study of Phonics Instruction: Teaching Phonics Dance to At-Risk Elementary Students to Improve Decoding Skills" (2011). Master of Education Research Theses. 34.

http://digitalcommons.cedarville.edu/education_theses/34 


\section{A STUDY OF PHONICS INSTRUCTION: TEACHING \\ PHONICS DANCE TO AT-RISK ELEMENTARY LEARNERS TO \\ IMPROVE DECODING SKILLS}

A thesis submitted in partial fulfillment

of the requirements for the degree of

Masters of Education

By

BRITTANY LEE PHIPPS

B.S. Early Childhood Education, Cedarville University, 2007

2011

Cedarville University 


\section{HEREBY RECOMMEND THAT THE THESIS PREPARED UNDER MY} SUPERVISION BY Brittany Lee Phipps ENTITLED A Study of Phonics Instruction: Teaching Phonics Dance to At-Risk Elementary Students to Improve Decoding Skills BE ACCEPTED IN PARTIAL FULFILLMENT OF THE REQUIREMENTS FOR THE DEGREE OF Master of Education.

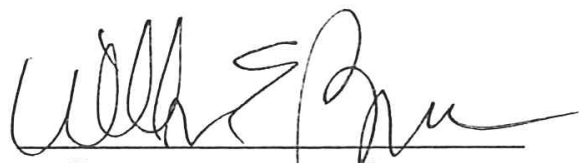

William E. Brown, Ph. D. President

\section{Mars MeClain}

Mark D. McClain, Ph.D. Associate Academic Vice President Dean, College of Professions

mergaret Mrgineno Margaret Grigorenke, Ph.D.

Thesis/Project Advisor
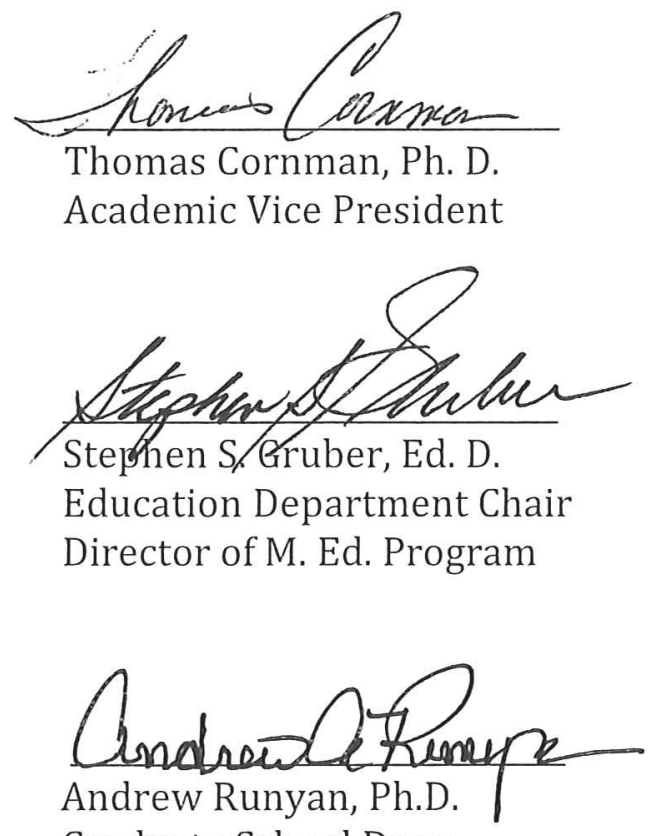


\begin{abstract}
Phipps, Brittany L. M.Ed., Education Department, Cedarville University, 2012. A Study of Phonics Instruction: Teaching Phonics Dance to At-Risk Elementary Students to Improve Decoding Skills.
\end{abstract}

The purpose of this study was to investigate the use of the Phonics Dance as an effective tool to aid low achieving students in their ability to decode words. Student and teacher perceptions of the Phonics Dance were also investigated to find out if this method is something that students enjoyed and preferred. A quantitative approach was used to determine the effectiveness of the Phonics Dance using a Pretest/Post-test approach with a control and a treatment group. Thirty-nine students received phonics instruction for four weeks. Students were assessed in their ability to read the sounds and digraphs taught to determine if the Phonics Dance was more effective in aiding students in their ability to decode words than the whole-language approach. The results were analyzed using a repeated measures ANOVA. While students showed significant difference between the Pre-test and the Post-test $(p<$ .0010), there was no significant difference found between the control group and the treatment group. 


\section{TABLE OF CONTENTS}

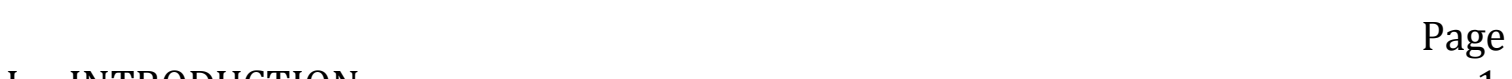

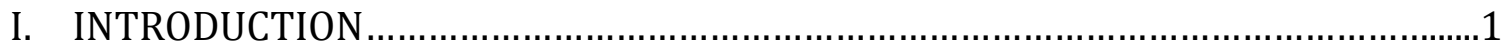

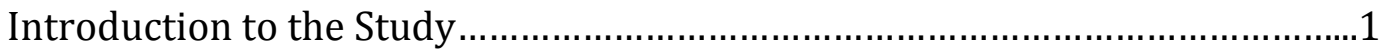

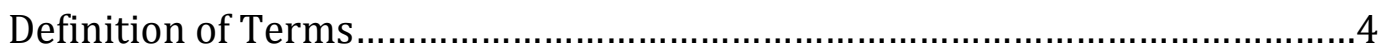

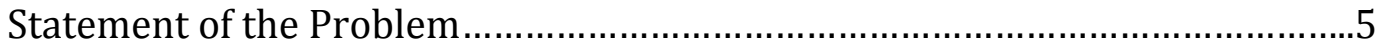

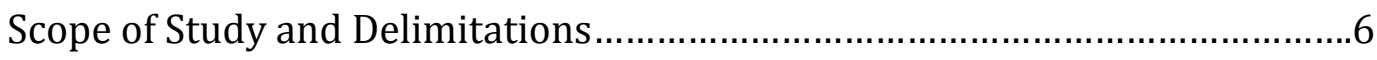

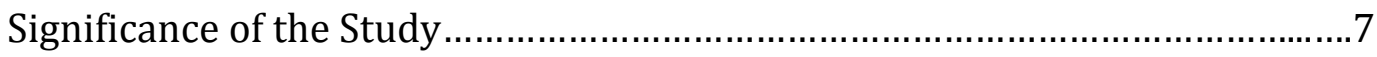

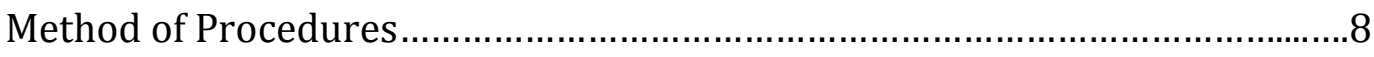

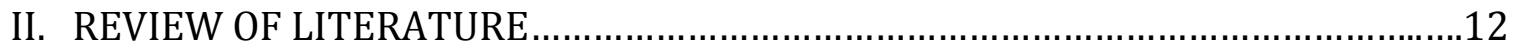

Overview of the Phonics Dance Program ...................................................12

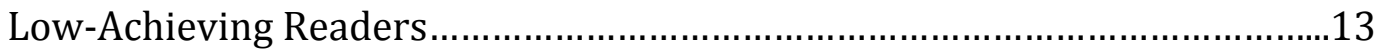

Data Concerning Low-Achieving Readers.....................................13

Importance of Instruction in Phonics for Low-Achieving Readers......15

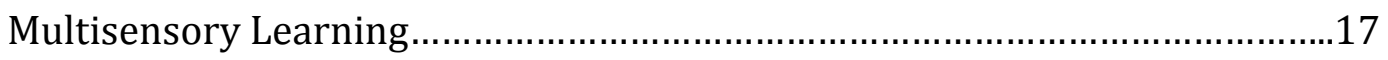

Auditory: The Use of Rhyme in Instruction.....................................17

Visual: The Use of Graphics in Instruction...................................18

Kinesthetic: The Use of Movement in Instruction.............................19

Current Research on the Phonics Dance ..................................................19

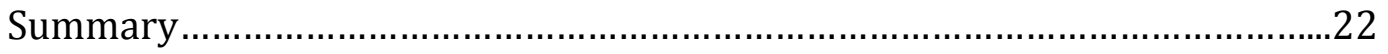

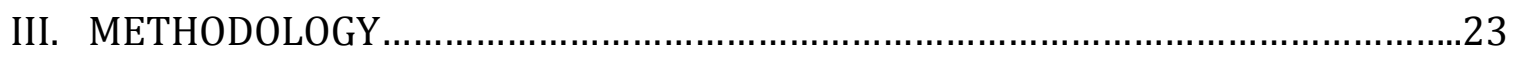

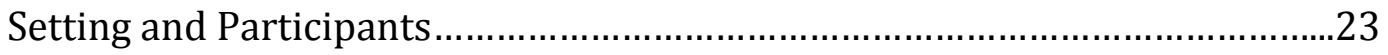

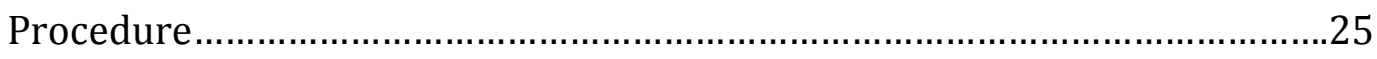

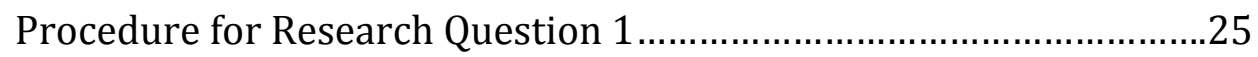




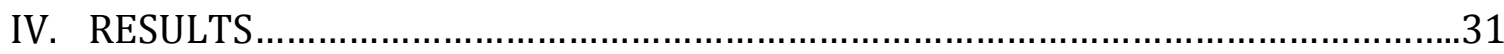

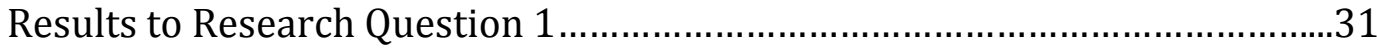

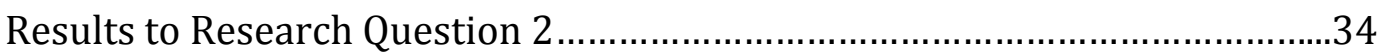

Observations of Student Perceptions...............................................35

Observations of Teacher Perceptions.............................................36

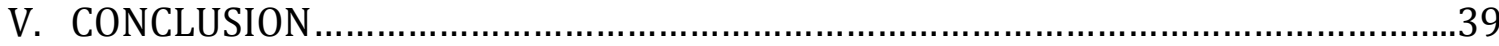

Application of Findings.........................................................................39

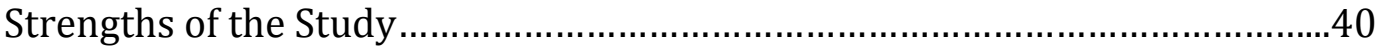

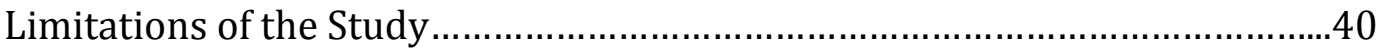

Suggestions for Further Research............................................................ 41

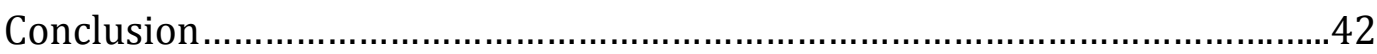

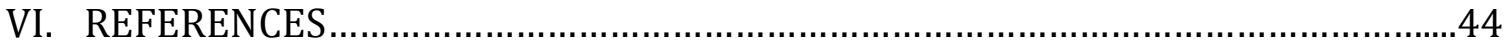




\section{LIST OF FIGURES}

1. Average of Gains by Grade Level.......................................33

2. Average of Gains by Gender....................................... 34 


\section{ACKNOWLEDGEMENT}

I give all praise to my God and Savior who is constantly molding me into the person and teacher that He wants me to be. I would like to thank my husband for his help, support, and endless patience with me throughout this endeavor. I would not be able to do this without him. I would also like to thank all the people that played a role in this study. My endless gratitude goes to Dr. Grigorenko, who spent hours editing, assessing, and guiding me; to Dr. Hwang, who answered endless statistics questions; to my principal and fellow teachers, who offered support and flexibility throughout this study; and to my students, who came willingly to work with me and gave their honest feedback. 


\section{CHAPTER ONE: INTRODUCTION}

Introduction

According to the 2003 National Assessment of Educational Progress (NAEP), thirty-seven percent of fourth graders and twenty-six percent of eighth graders cannot read at the basic level. This means that they are unable to accurately read, comprehend, and answer questions about an academic reading selection that is appropriate for their grade level. Moreover, even when students can read at the basic level, many times they are unable to read at an acceptable pace to achieve comprehension. Studies show that fifteen percent of all fourth graders read no faster than seventy-four words per minute, a pace at which it would be difficult to keep track of ideas as they are developing within the sentence and across the page (Pinnell, et. al. 1995). The ability of students to read words accurately and efficiently is essential to their comprehension of texts in order to meet school expectations. By the time that students reach the upper grades, they are expected to be able to fluently read and decode most words. When this is not possible for the student, they quickly fall behind not only in reading, but also in all content areas (Cunningham and Hall, 1998). Stanovich (1986) also noted that students who have early success in reading will often have future success in reading because of the increased numbers of words which they are exposed. He called this phenomenon the "Matthew Effect”, in which the good readers got better and the poor readers got poorer due to their inability to process as many words as better readers. With so many students struggling in 
reading grade level texts, schools are striving to establish new programs and methods to effectively provide instruction to these students.

Difficulty decoding words can often be a factor in students' struggles to read (Campbell, Helf, \& Cooke, 2008). These difficulties may arise because students have phonological deficits that create problems as the student strives to read (Ehri, Satlow, \& Gaskins, 2009). Students not only have to be able to understand the correlation between letters and sounds, but also have the ability to apply such generalizations to text in authentic reading situations (Heilman, 1976). To address these deficits in phonological awareness and decoding skills, schools typically provide phonics instruction in phoneme decoding, chunking, and analogy decoding. Arguments can be made for each type of instruction, however, "all necessary phonics skills needed by the child to become an independent reader should be taught” (Heilman, 1976). Phoneme decoding and chunking are usually taught in schools that use a phonics based reading program while analogy decoding is usually used in schools that employ a whole language reading program. Even with such programs in place, many students are not meeting grade level expectations in reading. Improved methods of teaching therefore may improve decoding skills for students who have not been successful with more traditional teaching methods.

Dowd (1999), a second grade teacher, developed a program in an attempt to meet her students reading needs. The program she developed is the Phonics Dance, a multisensory approach to phonics. According to the official Phonics Dance website (2010), the Phonics Dance uses a combination of visual, auditory, and kinesthetic-tactile strategies to address the student's needs. The wide range of intelligences that the Phonics Dance utilizes helps students to access the material regardless of their strengths and 
weaknesses. This allows a teacher to use the Phonics Dance as an entry point to "engage students and at the same time place them centrally within the desired literacy task (Gipe, 2002). The Phonics Dance teaches decoding using phoneme decoding and chunking. The Phonics Dance refers to both the program in its entirety and the first step of the program, which consists of the movements and chants that this program teaches students. Phonics Dance, as a program, has six steps that include sound attack, word work, creative writing, conferencing, treacherous word training, and reading. This program is designed for first and second grades in the general classroom and is intended to spiral so that students receive instruction on important concepts multiple times at planned intervals. Students receive instruction on a concept and review it daily for a time, then revisit it throughout first and second grade to ensure retention and internalization of the concepts and skills. The Phonics Dance, as step one of the program, is a series of chants and movements for long and short vowels, consonants, diphthongs, digraphs, and chunks. Students look at cards with the letter and a picture while reciting the chants and performing the motions. The program is designed so that students connect specific sounds with letters or letter combinations over time, starting with the most basic sounds and moving to the more difficult chunks. It is essential that students learn both the letter and their sounds individually but also the sounds that are made up of chunks of words and combinations of letters as they are exposed to more words. Recent brain research has suggested that the brain often functions in academics by detecting patterns and looks at clusters of letters (Cunningham and Hall, 1998). Because of this, it is essential to extend instruction to teach students to identify sounds using chunks, or clusters, of letters. Once the initial 
sounds and chunks have been taught, students participate in a daily review so that the correlation between the letters and sounds becomes easy and automatic.

\section{Definition of Terms}

Analogy Decoding - The process of decoding unfamiliar words by relating them to familiar words with similar letter patterns.

At-risk Readers - For the purpose of this study, at-risk readers is a label used by the school district to identify students who have performed poorly on the DIBELS assessment administered to them and are not meeting expectations for school performance.

Chunking- The process of decoding by identifying patterns of sounds that letters make. This process can also be referred to as pattern decoding.

$\underline{\text { DIBELS }}$ - DIBELS stands for Dynamic Indicators of Basic Early Literacy Skills. It is a reading assessment that is designed to pinpoint student progress and is used by schools to determine if students are reading on grade level or not. This assessment seeks to determine student reading fluency and comprehension of grade level texts.

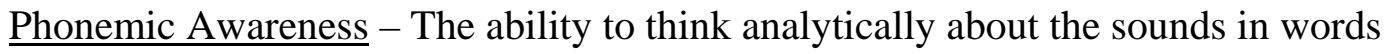
(Bukowiecki, 2007).

Phoneme Decoding - The process of decoding words by sounding out individual letter sounds and then blending the sounds to form the word.

$\underline{\text { Phonics }}$ - The process of linking sounds to their letter counterparts (Rule, Dockstader, \& Stewart, 2006). 


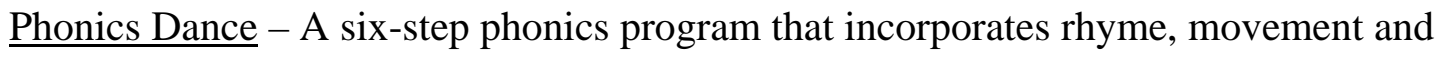
chant to teach letter sounds. It also breaks words into "hunks” and “chunks” for students to learn.

Phonological Awareness - A broad category of language, which refers to the awareness of and the ability to manipulate words, syllables, rhymes, and sounds (Bukowiecki, 2007).

Whole Language - A method of teaching reading and writing that emphasizes learning whole words and phrases by encountering them in meaningful contexts rather than by phonics exercises.

Statement of the Problem

Phonics Dance is an instructional method that has been shown to produce positive results in instruction for beginning readers (Bostelman, 2008). There have been some studies regarding its effectiveness for phonics instruction in its intended areas of first and second grade. Studies found that teachers who used the program considered it to be an effective tool for phonics instruction and felt that students utilized the skills taught through the Phonics Dance while reading and decoding unknown words (Longmire, 2008). One study found that the Phonics Dance was effective at promoting reading fluency, but not significantly more so than many other phonics programs (Boertje, 2009). Another study was designed to investigate its effectiveness in developing early phonological and phonemic awareness. The study showed an improvement in the letter naming and initial sound fluency of students being taught using the Phonics Dance, although the study did not determine is the program was more effective than any other teaching strategy (Bostelman, 2008). The Phonics Dance is a program used by some 
schools for phonics instruction for the early primary grades and as a supplement for other reading programs in the primary grades.

However, almost no research has been done to explore possible uses for the Phonics Dance as intervention tool for older readers, specifically students in first through fourth grade, who are struggling to consistently decode words. Because of its interactive and repetitive nature, the Phonics Dance could potentially be a useful and inexpensive tool for intervention teachers and general education teachers who are supplementing curriculum to meet the needs of readers in their classroom who are at-risk for reading failure.

Scope of the Study and Delimitations

This study focused solely on the effects of the Phonics Dance as an intervention tool for elementary students in grades first through fourth. I used an experimental design to study the academic outcomes of the use of Phonics Dance in intervention instruction by assessing students' abilities to read words, nonsense words, and words within a text before and after instruction. The study also examined student perceptions of the Phonics Dance and its effectiveness. The aim of the study was to compare the use of Phonics Dance, which teaches phoneme decoding and chunking, with the use of a whole language approach, which teaches decoding through analogy decoding.

This study was conducted at a public school in a Midwestern state. The school is a Title 1 school, indicating that over seventy-five percent of the students come from families that have a low socio-economic status. The students were selected based on their DIBELS scores, which determined that students were "at-risk" for reading failure based on school expectations. All the students in the school that met the grade and reading 
ability specifications set forth by the researcher were included in the study. Because of various backgrounds, some students had received phonics instruction using the Phonics Dance previous to the study and some had not. Most students had received reading instruction primarily using a whole language approach and exposure to analog decoding skills. Thirty-nine students participated in the study.

\section{Significance of the Study}

Because of limited time in the classroom, educators should explore the effectiveness of each reading program before establishing it as an instruction method for intervention. The large number of students facing school reading failure and the increased pressure that teachers and schools are experiencing to demonstrate reading success for all students often leads to an increased number of interventions and teaching strategies in the classroom. However, it is essential that these methods and interventions be thoroughly researched, studied, and evaluated so that classroom time is used effectively.

The current research addresses the use of Phonics Dance for phonics instruction in the general classroom but does not address its use as an intervention tool. This research expands current available research by testing the effectiveness of the Phonics Dance on an "at-risk" population. This study will also observe the effect of the Phonics Dance on older students who have not mastered basic phonics skills and are unable to decode words independently. It focuses both on the academic outcomes of using the Phonics Dance for intervention as well as on student perceptions and feelings toward the program. In this research, I seek to evaluate the effectiveness of the program with an expanded age bracket to determine whether older students and students who have not responded to typically used curriculum can benefit from the program. In order to assess this it is 
essential to evaluate the students' thoughts and opinions toward the program to determine if its use is demeaning or too juvenile for the older students. This study strives to ascertain if the Phonics Dance is an effective method of phonics intervention. The study also seeks to expand both the uses and the age bracket of the Phonics Dance. Methods of Procedures

\section{Research Questions:}

1. Is the Phonics Dance a more effective intervention tool in aiding lowachieving first through fourth grade reading students in their ability to decode words than a whole-language approach?

2. What is the response of students and teachers to the use and effects of the Phonics Dance in the classroom?

This experimental method was conducted in two parts. The first and primary part of this research assessed the use of the Phonics Dance to teach students to decode words and whether the Phonics Dance was a more effective tool for intervention students than a whole language approach. This was a quantitative design in which students were administered a pre- and post- test. The results were analyzed using a repeated measures analysis of the variance (ANOVA). Scores were analyzed as a group, by grade level, and by gender to study whether or not the Phonics Dance was more effective for a specific age group or gender. This was the central focus of the study. The secondary portion of this study investigated student perceptions of the Phonics Dance and was conducted in a qualitative manner. This portion consisted of field notes and the researchers' observations of the reactions and perceptions of the students during instruction and was conducted to support and add validity to the use of the Phonics Dance as an intervention tool. 
Students were chosen from grades first through fourth from an elementary school. Students were selected based on their oral reading fluency taken using the Oral Reading Fluency (ORF) assessment of DIBELS, a standardized reading assessment that records words of a passage read accurately in a minute. All students in the target school participate in the Oral Reading Fluency assessment of DIBELS at the beginning, middle, and end of the school year and this is the primary assessment used at the target school to identify low-achieving readers. Students who were chosen were classified as at-risk based on these scores as follows; zero to seven wpm (words per minute) for first grade students, zero to fifty-one wpm for second grade students, zero to sixty-six wpm for third grade students, and zero to eighty-two wpm for fourth grade students. To ensure consistency, the DIBELS scores that were used were the ones taken during the mid-year benchmark. Thirty-nine students were identified for this study. Ten students were taken from grades first, second, and third. Nine students were taken from fourth grade. The students included in the study had no diagnosed disability and did not have an Individualized Education Plan. In first grade, seven of the participating students were boys and three were girls. Of the students selected in second grade, seven students were boys and three were girls. In third grade, five of the students were boys and five of the students were girls. Of the students selected for fourth grade, four of the students were boys and five of the students were girls. Overall, twenty-three of the students included in the study were boys and sixteen of the students were girls. Of the students included in the study, twentynine students were White, nine students were Black, and one student was Asian and spoke English as a second language. I was unable to obtain information on the socioeconomic status of the specific students included in the study. 
The research was conducted at the students' school over the course of four weeks. Instruction was conducted at a consistent time in the morning and each lesson took a total of ten minutes. Students received instruction three days a week. All students received instruction in phonics. Phonics instruction was given using two methods. Students in each grade were randomly assigned to receive either the whole-language instructional method or the Phonics Dance method. Students given instruction using the whole-language approach were the control group for the treatment group, which received instruction using the Phonics Dance method. I strove to include the same number of students in each group, but due to scheduling conflicts with the teachers of the selected students, some groups had more students than others. Each group had between four to six students. The whole-language method involved students reading a sentence, identifying a word in the sentence that had the targeted sound, and then discovering other words that had the same sound. The Phonics Dance method involved students learning a rhyme and dance that correlated to a specific sound and then collecting words that had that sound. Students learned new sounds two days a week. They also spent one day reviewing the sounds that they had previously learned. A script was followed to ensure consistency and reliability. Both groups covered identical phonics concepts and learned a total of eight new sounds throughout the course of the study.

Students were given a pre-test before receiving instruction. The pre-test was administered individually in a private room. The test required students to read words in a list form, nonsense words in a list form, and words within a text that contain the phonics sounds that were taught. Errors were marked on a separate scoring sheet by placing either an "x" or a check by the word being read. If any sounds within the nonsense words were 
read incorrectly, then the word was scored as an error. Sounds were considered incorrect if they were not phonetically correct and did not make a sound that a particular letter is known to make. If the student read any sounds in the words in list form incorrectly then the entire word was scored as an error. In scoring the portion of the assessment in which students had to read words within a context, or words within a paragraph, the students only received errors if they were unable to correctly read one of the targeted words that contained the taught sounds. All students were administered a post-test identical to the pre-test following instruction. Pre-test and post-test scores were analyzed to determine if there is significant difference in scores. The scores were determined as significant based on a significance level of 0.05 . I completed a repeated measures analysis of variance (ANOVA) on both the pre-test and post-test mean scores using SPSS. A repeated measure ANOVA was also performed on the pre-test and post-test scores of each grade level and gender to help determine if one instructional method was more effective for certain grade levels or genders than others.

During instruction, I recorded any observations on student perceptions of the Phonics Dance program. This included notes on student participation, attitude, and demeanor during instruction as well as included any comments that students made during instruction on their feelings towards the program. This was done to gain insight into the students' perceptions and feelings toward the program and to determine if students felt positively or negatively toward the program. I also documented conversations that I had with other teachers to explore the feeling and opinions that the teachers had on the program and the effect that the treatment had on the students both academically and behaviorally. 


\section{CHAPTER 2: REVIEW OF LITERATURE}

Overview of the Phonics Dance Program

The Phonics Dance reading program was developed by a first grade teacher, Ginny Dowd, who noticed that her students were unable to spell words accurately because they were unable to decipher the sounds and determine which letters to use. She also noticed that many of the words that her students were required to read contained diphthongs and digraphs that had not been taught. The reason for this was that although eighty-four percent of the words in the English language are phonetically correct, the sixteen percent of words that are not phonetically correct appear in literature eightypercent of the time (Dowd, 1999).

To address her students’ needs in this area, Dowd developed a program following some basic principles. The first principle is the idea that not all students grasp concepts at the same time and that learning takes repetition. The Phonics Dance is a spiral program that allows students to learn and review the sounds daily so that they will master the concepts at their own pace and retain this information. Another principle that guides this program is the idea that "the brain is a pattern seeking device rather than a rule applicator” (Dowd, 1999). Instead of teaching phonics rules, the program teaches letter patterns that students will learn to recognize as they see the patterns within new words and words within contexts. 
The program has expanded from the actual Phonics Dance, which consisted of just chants and kinesthetic movements to a complete program with reading and writing. Dowd has also begun to branch into applying some of her principles to math activities. While the program is relatively new and is becoming increasingly widespread, there has not been extensive research done to verify its effectiveness as a reading program.

This chapter will discuss the literature related to the low-achieving readers within school, including studies that outline the prevalence of such students as well as possible causes for their low reading achievement on school texts. The Phonics Dance includes several different aspects, including the use of visual, kinesthetic, and rhyming strategies in order to help students internalize the letter/sound correlations in reading. Research regarding the use of each of these strategies will be discussed. Results from studies that have been conducted regarding the Phonics Dance previously will also be included in this chapter.

\section{Low- Achieving Readers}

\section{Data Concerning Low-Achieving Readers}

There are a large number of students who are not demonstrating the ability to read well enough to meet the educational demands necessary in order to reach educational success and future economic success (National Academy of Sciences). Studies show that there are not only a large percentage of elementary students reading below a basic level, but the trend continues through high school and into adulthood. According to the National Center for Educational Statistics, twenty-two percent of adults in the United States are operating below a basic level, meaning that they have no more than the most basic and concrete reading skills. 
In 2009, twenty-nine percent of fourth graders in Ohio scored below a basic reading level on the NAEP reading assessment. Thirty-four percent of fourth grade students throughout the United States scored below a basic reading level. While reading scores have improved since 1992, when the NAEP started assessing students in reading and mathematics, the number of students who are unable pass assessments of grade level reading comprehension is still sizeable. However, there was no significant improvement in students' scores between 2007 and 2009.

The NAEP National Report Card for 2009 showed that males scored lower than females in reading assessments on average. Moreover, students from low-socioeconomic families and minorities also tend to score lower than average on reading assessments. These findings are reflected in the population of the current study in that all of the students included were from low socioeconomic homes and the majority of the students included were males.

With over a quarter of the students in fourth grade unable to pass assessments of reading grade-level texts, it is important that teachers develop ways to meet these students' needs in within the classroom. The Committee on the Prevention of Reading Difficulties in Young Children states that:

There are three potential stumbling blocks that are known to throw children off course on the journey to skilled reading. The first obstacle, which arises at the outset of reading acquisition, is difficulty understanding and using the alphabetic principle - the idea that written spellings systematically represent spoken words. It is hard to comprehend connected text if word recognition is inaccurate or laborious. The second obstacle is a failure to transfer the comprehension skills of 
spoken language to reading and to acquire new strategies that may be specifically needed for reading. The third obstacle to reading will magnify the first two: the absence or loss of an initial motivation to read or failure to develop a mature appreciation of the rewards of reading (Committee on the Prevention of Reading Difficulties in Young Children).

Teachers need to work on developing strategies and activities to bring students past these and other obstacles and put them on the path to reading success. To meet the diverse needs of students, "teachers often need to follow diverse philosophies of instruction. Additionally, these philosophies need to be studied, analyzed and implemented in whole or in part while the teacher remains cognizant of the implications for each philosophy” (Ediger, 2010).

Importance of Instruction in Phonemic Awareness and Phonics for LowAchieving Readers

A study conducted by the National Reading Panel "showed that teaching children to manipulate phonemes in words was highly effective under a variety of teaching conditions with a variety of learners across a range of grade and age levels and that teaching phonemic awareness to children significantly improves their reading more than instruction that lacks any attention to PA.” (National Reading Panel, 2000). Many studies have also shown the importance of teaching phonemic awareness, especially to lowachieving readers and students who come from low socio-economic homes. The Report of the National Reading Panel, which was conducted by the National Institute of Child Health and Human Development (2000) found that: 
Systematic synthetic phonics instruction had a positive and significant effect on disabled readers' reading skills. These children improved substantially in their ability to read words and showed significant, albeit small, gains in their ability to process text as a result of systematic synthetic phonics instruction. This type of phonics instruction benefits both students with learning disabilities and lowachieving students who are not disabled. Moreover, systematic synthetic phonics instruction was significantly more effective in improving low socioeconomic status (SES) children’s alphabetic knowledge and word reading skills than instructional approaches that were less focused on these initial reading skills. Fountas and Pinnell (2009) also recommend the use of explicit systematized phonics instruction in reading instruction and intervention.

Pinnell and Fountas (2009) found that while instruction in phonemic awareness and phonics are widely proven to be necessary for reading success in kindergarten through second grade, many students develop masking techniques that allow them to move through the younger grades without truly gaining an understanding of how print works and developing the ability to manipulate letters and sounds. As students move to more challenging and foreign texts, they are unable to decode academic texts with sufficient speed and accuracy that allows them to meet school demands, and frequently develop poor attitudes about reading and themselves as readers. By providing a good, comprehensive program that utilizes instruction in phonemic awareness and phonics, students will be more likely to obtain these skills, which may lead to better reading ability as they develop. Some students reach the older elementary grades without developing the skills needed to be fluent readers. To meet these students' needs, intervention is often 
needed in phonics and phonemic awareness so that they can move forward in the reading process (Pinnell \& Fountas, 2009).

\section{Multisensory Learning}

Despite the limited research done specifically on the Phonics Dance, much research has been done on the use of multisensory teaching techniques to promote learning. The Phonics Dance utilizes a multisensory approach to phonics instruction through a combination of visual, auditory, and kinesthetic tools to teach alphabetic sounds and chunks.

Multisensory instruction is supported by many researchers (Willis, 2007; Henry, 2003; Neumann, 2004; Minskoff, 2005; Armstrong, 2000) and has been a part of many studies and allows the teacher to meet the needs of students who have a variety of learning styles in an effective manner. Instruction that uses more than one sensory experience, such as auditory, visual and kinesthetic tools, connects multiple brain regions to the content being taught and provides multiple paths for students to access the information (Willis, 2007). Moreover, the use of multisensory instruction allows all students to simultaneously link together what they see, what they hear, and what they feel (Henry, 2003). The following sections will address each of these areas more specifically.

Auditory: The Use of Rhyme in Instruction

The use of rhyme and music has been shown to increase phonemic and phonological awareness. Neumann (2004) found that texts and activities that utilized music and rhyme assisted children as they gained phonological and phonemic awareness. Moreover, studies have shown that the use of rhyme has been beneficial in teaching 
children to hear and differentiate between letter sounds and better understand the relationship between sounds, leading to early reading (Foy and Mann, 2006).

Lombardo (2005) also found that the use of rhyme enhanced students' ability to read. She found that combining chants and rhymes with visual representations and movements benefitted the students. She also used rhymes and chants to teach students word families and alliterations. Lombardo found that rhymes not only helped younger students in their reading development, but that older students also benefitted from the use of rhymes in the classroom.

The above researchers agree that the use of rhymes within the classroom leads students to the ability to differentiate between letters and sounds and are useful tools in reading instruction. They equip children with the ability to hear and manipulate individual phonemes and sounds, which is necessary in order for children to become successful readers.

\section{Visual: The Use of Graphics in Instruction}

The number of students who learn visually has increased over the past twenty-five years to almost fifty percent of all students (Willis, 2007). Minskoff (2005) suggests that best practice in the classroom is to associate words that the student is learning visually with objects, pictures, or demonstrations whenever possible. Placing the word that the student is learning aside the picture of the object is an easy and efficient way to promote learning in students. For example, teachers can write color words in the color it represents or write the letters of the word "down" in a descending fashion. The use of pictures and even crude, graphic symbols can aid some students in the understanding of concepts (Armstrong, 2000). While the use of pictures and graphics are traditionally used more in 
the primary grades, Armstrong considers its use to be very effective for older students as well.

\section{Kinesthetic: The Use of Movement in Instruction}

Studies have shown that thirty-five percent of students are bodily-kinesthetic learners and many teachers do not teach reading in a way that meets these students specific learning style. Bodily-kinesthetic learners use body movement to connect with information and solve problems (Willis, 2007). Willis states that physical movement is important for kinesthetic learners and "links the material to be learned with sensory input, thereby increasing access to the brain’s memory banks”. Longmire (2008) found that many teachers felt that motions and movement motivated their students and got them excited about learning. Asking students to pantomime concepts or ideas from a lesson requires them to translate verbal/linguistic information into a bodily/kinesthetic expression, which some students can better process and recall (Armstrong, 2000).

\section{Current Research on the Phonics Dance}

There has been limited research conducted on the effectiveness and the perceptions related to the Phonics Dance. I was able to find and obtain three studies that have been conducted on the use of the Phonics Dance that assessed the Phonics Dance in relation to teacher perceptions, effectiveness in increasing oral reading fluency, and effectiveness in increasing phonemic and phonological awareness skills.

Longmire (2008) completed a study on teachers' perceptions of the Phonics Dance. This thesis study consisted of a survey that involved eighty-three participants and included teachers from all over Ohio. The participating teachers taught grades first through third and had used the Phonics Dance previously or were currently using the 
program. Teachers responded on topics including their comfort level in using the program, teacher training, student benefit and student performance, application of the six steps of literacy, and student enjoyment. The questions used a Likert scale with two openended questions also included.

The first topic, the comfort level of teachers using the program, showed that ninety-eight percent of teachers involved in the study liked using the program and ninetyfive percent of teachers stated that they felt comfortable using the program. Ninety-one percent of teachers communicated that they felt properly trained to teach the Phonics Dance. The study also showed that ninety-six percent of the teachers participating in the study believed that their students could see how the Phonics Dance could help their reading and writing and eighty-four percent of the teachers said that they had seen their students using the concepts used in the Phonics Dance during reading. Eighty-eight percent of the teachers involved in the study believed that their students enjoyed the program. Moreover, one hundred percent of teachers believed that most of their students benefitted from the use of the Phonics Dance in their classroom. Teachers also noted the importance of consistently reviewing the chants.

Overall, Longmire reported that teachers found the Phonics Dance to be easy and efficient to teach. Teachers felt that students enjoyed the program and utilized the concepts and strategies taught in the Phonics Dance (Dowd, 1999).

Another study observed the effectiveness of the Phonics Dance on reading fluency. Boertje (2009) used DIBELS to ascertain the effect of teaching the Phonics Dance on reading fluency in second grade students. The study consisted of six classrooms at a public school in Ohio, three of the classes served as a control group for 
the study and three classes received the Phonics Dance treatment. The researcher used the Oral Reading Fluency portion of DIBELS to assess students' fluency. Fluency scores were taken for all students at the beginning, middle and end of the year. The scores were the analyzed using visual analysis descriptive statistics and a t-test. The researcher found that the students who received instruction using the Phonics Dance performed slightly better than the students that did not receive the treatment, however, the results showed that the scores between the control and treatment groups were not significantly different. On average, the study showed that students participating in the Phonics Dance increased their words per minute growth by .04 words weekly over that of the control group.

Boertje also surveyed the teachers using the Phonics Dance to evaluate their thoughts and feelings regarding the Phonics Dance. He used a Likert scale to assess their response on ten questions regarding the effectiveness of the Phonics Dance in their classroom. The teacher responses ranged from 3.6 to 4.6 on a 5.0 scale, however, the responses were not analyzed to determine areas of weakness or strengths.

While the previous studies analyzed the use of the Phonics Dance within the targeted age group of first through third grade, Bostelman (2008) studied the use of the Phonics Dance in a preschool classroom. This study looked specifically at the effects of the rhyme and chants that are used in the Phonics Dance on preschool students' phonological and phonemic awareness skills. The study examined sixteen students, age three through five, who were enrolled in a small, rural school.

Bostelman used the alphabet chant portion of the Phonics Dance throughout the year. The researcher used the initial sound fluency and letter naming portions of DIBELS to assess students at the beginning of the study, monthly throughout the treatment, and at 
the end of the study. The results of the DIBELS scores were than analyzed to determine if the use of rhymes and music helped preschool students increase their basic phonological and phonemic awareness. At the beginning of the study, students were able to name 4.62 letters per minute on average. Each month, the scores rose and at the final assessment, students were able to name an average of 13 letters per minute. The researcher also examined students’ ability to recognize letter sounds. At the beginning of the study, students were able to recognize an average of 1.77 sounds per minute. At the end of the study, students were able to name an average of 2.043 sounds per minute.

Bostelmen determined that the study conducted did indicate that the Phonics Dance promoted student's acquisition of phonological and phonemic awareness skills. The results showed an overall improvement in both the letter naming and initial sound fluency throughout the treatment.

\section{Summary}

The literature shows that many students are not successfully meeting the expectations that schools have regarding reading. Instruction in phonemic awareness may help struggling students, along with systematic, synthetic phonics instruction. Studies have shown that multi-sensory and kinesthetic learning approaches have also been shown to be effective in improving learning for struggling students. Previous studies on the Phonics Dance have shown that it is an effective tool for increasing phonetic and phonemic awareness. It has also shown that many teachers find that it aids their students in reading and motivates them, despite research that shows that there is not statistical difference in reading fluency rate between students who received instruction using the Phonics Dance and students who did not. 


\section{CHAPTER 3: METHODOLOGY}

\section{Setting and Participants}

This study was conducted at an elementary school in a Midwestern state. The target school was one school out of seven elementary schools within the district. The school is located in a rural area and the district is in a low socio-economic area. According to the online data provided by the state's Department of Education, the racial distribution for the district included 14\% Black, 0.4\% Asian or Pacific Islander, 0.9\% Hispanic, 7\% percent Multi-Racial, and 78\% White. Of the students enrolled in this district, 46.2\% come from families that are economically disadvantaged and $15.2 \%$ of students had a disability, and $0.4 \%$ of students were English Language Learners.

The targeted school's daily enrollment for the 2009-2010 school year was 420 students, preschool through fifth grade. The racial distribution for the school included 11.4\% Black, 10.1 Multi-Racial, and 76.6\% White. Out of the students enrolled in the targeted school, $16.5 \%$ had a diagnosed disability and $52.8 \%$ of students came from families that are economically disadvantaged.

The current study focused on first through fourth grade students. Students included in the study came from eleven different classrooms in the targeted school. There were thirteen classrooms in the targeted grades, however, two teachers did not allow their students to participate in the study leaving me with eleven classrooms to pull from. 
The students included in the study were selected from the above classrooms to participate based on their DIBELS scores. I wanted to study the effects of the Phonics Dance on low-achieving students who did not have a diagnosed disability. Students were selected based on their oral reading fluency taken using the Oral Reading Fluency (ORF) assessment of DIBELS, a standardized reading assessment that records words of a passage read accurately in a minute. Students who were chosen were classified as "atrisk" for reading failure based on their ORF scores as follows; zero to seven wpm (words per minute) for first grade students, zero to fifty-one wpm for second grade students, zero to sixty-six wpm for third grade students, and zero to eighty-two wpm for fourth grade students. To ensure consistency, the DIBELS scores that were used were the ones taken during the mid-year benchmark.

All the students who met the above criteria were included in the study. The researcher included ten students from first grade, ten students from second grade, ten students from third grade, and nine students from fourth grade. In first grade, seven of the participating students were boys and three were girls. Of the students selected in second grade, seven students were boys and three were girls. In third grade, five of the students were boys and five of the students were girls. Of the students selected for fourth grade, four of the students were boys and five of the students were girls. Overall, twenty-three of the students included in the study were boys and sixteen of the students were girls. Of the students included in the study, twenty-nine students were White, nine students were Black, and one student was Asian and spoke English as a second language.

The students were divided into two groups for the study to make up the control group and the treatment group. In order to decrease the disruption to the students' normal 
class day and to each participating teacher's class day, students were assigned to groups along with the other participating students from their class. Because there were an uneven number of students from particular classrooms selected for the study, some groups had an uneven number of students. In first grade, six students were included in the treatment group and four students were included in the control group. In second grade, five students were included in both the control and the treatment group. In third grade, five students were included in both the control and the treatment group. In fourth grade five students were included in the treatment group and four students were included in the control group.

Classes were assigned to either the treatment group or the control group randomly. This assignment was done prior to any analysis done on the students’ DIBELS scores and prior to the pre-test being administered to the students.

Permission was granted to the researcher by the principal of the targeted school and the individual teachers of the students to conduct the study. This permission was requested to use the student's data that had been previously generated by the teachers and to pull students during the class day to conduct the treatment and necessary assessments. In order to ensure the population size and because of the absence of any possible harm to the students, parent permission was not requested.

Procedure

\section{Procedure for Research Question 1}

The first inquiry that the researcher researched was whether the Phonics Dance was a more effective intervention tool in aiding low-achieving first through fourth grade 
reading students in their ability to decode words than a whole-language approach. The researcher utilized a quantitative, pre-test/post-test design in order to answer the first research question regarding the effectiveness of the use of the Phonics Dance on the decoding skills of low-achieving readers.

Students were administered an identical pre-test and post-test prior to and following the four weeks of treatment. The assessment was designed to assess student's ability to decode nonsense words, familiar words, and words within a context. The assessment included sixteen nonsense words, sixteen familiar words, and eight words within a paragraph. The words in the assessment contained eight targeted sounds that were taught during the treatment process. The assessment was administered individually to each student in a private room by the researcher. A script was followed to ensure consistency in the assessment. The assessment took between five and ten minutes per students, depending on the time that the students spent decoding the words.

The students were required to read the words on the page and the researcher marked correct and incorrect responses on a separate scoring sheet. The researcher marked errors on a separate scoring sheet by placing either an "x" or a check by the word being read. If any sounds within the nonsense words were read incorrectly, then the word was scored as an error. Sounds were considered incorrect if they were not phonetically correct and did not make a sound that a particular letter is known to make. If the student read any sounds in the words in list form incorrectly then the entire word was scored as an error. In scoring the portion of the assessment in which students had to read words within a context, or words within a paragraph, the students only received errors if they were unable to correctly read one of the targeted words that contained the taught sounds. 
The other words within the paragraph were there to provide context and remained unscored.

There were two separate assessments, one assessment was for the first and second grade students and one was for the third and fourth grade students. Both tests contained sixteen nonsense words, sixteen words in a list form, and eight words within a context however, the words included were different. This was because the first and second graders focused on different sounds than the second and third grade students. However, the format of the two assessments were the same. This was done so that the sounds that the students were learning were appropriate to the students' current level of reading.

The pre-test was administered during the week prior to the treatment and the posttest was administered to the students during the week following the treatment. In order to improve reliability, the researcher marked students responses while the students were reading. The researcher then had an assistant mark a separate scoring sheet for each child while listening to the recording to ensure accuracy. Any inconsistencies found during this process were re-evaluated by both the researcher and the assistant to determine the correct marks. No personal information of the child was released to the research assistant in order to preserve students’ confidentiality.

Following the pre-test, the treatment was conducted. Students received instruction three times a week for four consecutive weeks. Each session lasted seven to ten minutes. The sessions were administered in a group setting with four to six students at a time. The students had their session at the same time each day and each session was administered in the same location, with the exception of two sessions, which were held in the library due to classroom scheduling conflicts. 
Half the students were in the control group and received instruction from me using a whole-language approach. The treatment group received instruction from me using the Phonics Dance. All first and second graders received instruction on the same sound chunks and all third and fourth grade students received instruction on identical sounds. All students learned two new sound chunks each week and had one day dedicated to review sounds that they had learned previously. Over the course of the four weeks, the students learned eight new sounds. They spent eight days learning new sounds and four days reviewing the sounds that they had learned.

The researcher followed a script in each session to ensure the validity of the treatment. The format for the whole-language approach lesson was as follows: Two minutes spent reading a sentence that had multiple words with the targeted sound and identifying the sound. Five to eight minutes discovering words that shared the target sound. The review session involved students reading and writing words that contained the targeted sounds that had been previously taught.

The format for the Phonics Dance lesson was as follows: One minute introducing the new sound and chant with motions. Two minutes performing the chant as a group. Two to five minutes discussing words that had the targeted sound. Two minutes reviewing the chant with the students. The review session involved students doing all the chants and motions for the sounds that had been previously taught two to three times.

Following the post-test, the student scores were analyzed to determine the effectiveness on the interventions. A repeated measures ANOVA was used on both the pre-test and post-test mean scores. A repeated measures ANOVA was also performed on 
the pre-test and post-test scores of each grade level and gender to help determine if one instructional method was more effective for certain grade levels or genders than others.

\section{Procedure for Research Question 2}

The second inquiry that the researcher strove to explore was the response that students and teachers had to the use and effectiveness of the Phonics Dance. The researcher used a qualitative approach to explore this question. The researcher conducted a naturalistic inquiry in which the researcher acted as a participant observer.

During instruction, I recorded any observations on student perceptions of the Phonics Dance program. This included notes on student participation, attitude, and demeanor during instruction as well as included any comments that students made during instruction on their feelings towards the program. It also included academic progress and difficulties that the researcher observed during the treatment. Following each session, I expanded on observations that had been jotted down to include any observations made. Students were encouraged to share their opinion of the program while walking back and forth from their classroom to the room where the treatment took place.

The researcher also frequently discussed the use and effects of the Phonics Dance with the students' teachers and administrators. Comments made by teachers independently and throughout discussions were recorded. Questions regarding student behavior prior to and following the treatment, academic development and changes following treatment, and changes in student behaviors were brought to the teachers and administrator for discussion. The researcher spoke to the teachers individually as well as in casual group settings. Notes were taken following every discussion had with the teachers to ensure the inclusion of all thoughts the teachers conveyed. 
All the comments and observations regarding the use and effectiveness of the Phonics Dance were analyzed for themes. Separate themes were found for observations made about students' thoughts and opinions and observations obtained about the teachers' thoughts and opinions. The researcher was particularly interested in the response of students of different ages and gender had to the use of the Phonics Dance and the behavioral changes that the teachers observed once the students had returned to the classroom. 


\section{CHAPTER 4: RESULTS}

The purpose of this study was to determine if using the Phonics Dance as an intervention tool was an effective method of intervention in aiding students in their ability to decode words and to determine if it was more effective than a whole language approach. The study also strove to explore the attitudes and perceptions of the students and teachers towards the Phonics Dance. Following the treatment the students' pre-tests and post-tests were analyzed to find out if there was a significant difference between the students receiving instruction using a whole-language approach and students receiving instruction using the Phonics Dance. The field notes that were taken were also analyzed for themes immediately following the administration of the students' post-tests.

\section{Results to Research Question 1}

The primary research question was assessed using the pre-test and post-test scores from the students' assessments. These scores were analyzed using a repeated measures analysis of the variance (ANOVA).

The students in both the control group and the treatment group showed statistically significant between the pre-test and post-test when scores were analyzed using a repeated measures ANOVA $(p<.0010)$, showing that both methods of instruction were effective in improving students' abilities to decode phonetically correct words.

Students receiving the treatment gained 7.1 words (read an average of 7.1 more words correctly) while the students in the control group gained and average of 2.89 words 
between the pre-test and the post-test. While students in the treatment group as a whole had a larger gain than the students that were in the control group, after running a repeated measures ANOVA, the results were not found to be statistically different $F(1,37)=.001$, $p=.978$.

In first grade, the students in the treatment group gained an average of 6.83 words while the students in the control group gained an average of 8.25 words. There was no significant difference between the treatment group and the control group, $F(1,8)=1.285$, $p=.290$. In second grade, students in the treatment group gained an average of 5.8 words while students in the control group lost 0.6 words. Second grade did not have a significance difference either, $\mathrm{F}(1,8)=4.850, p=.059$. In third grade, students in the treatment group gained an average of 11.4 words and the students in the control group gained an average of 3.6 words. Third grade did not have a significant effect $F(1,8)=$ $1.891, p=.206$. In fourth grade, students in the treatment group gained an average of 4.4 words while students in the control group gained an average of 1 word. Fourth grade did not show a significant difference, $\mathrm{F}(1,7)=.647, p=.448$. None of the grades showed a significant difference in gains between the control group and the treatment group. Figure 1 below visually shows the average difference in gains between the control group and the treatment group by grade level. 


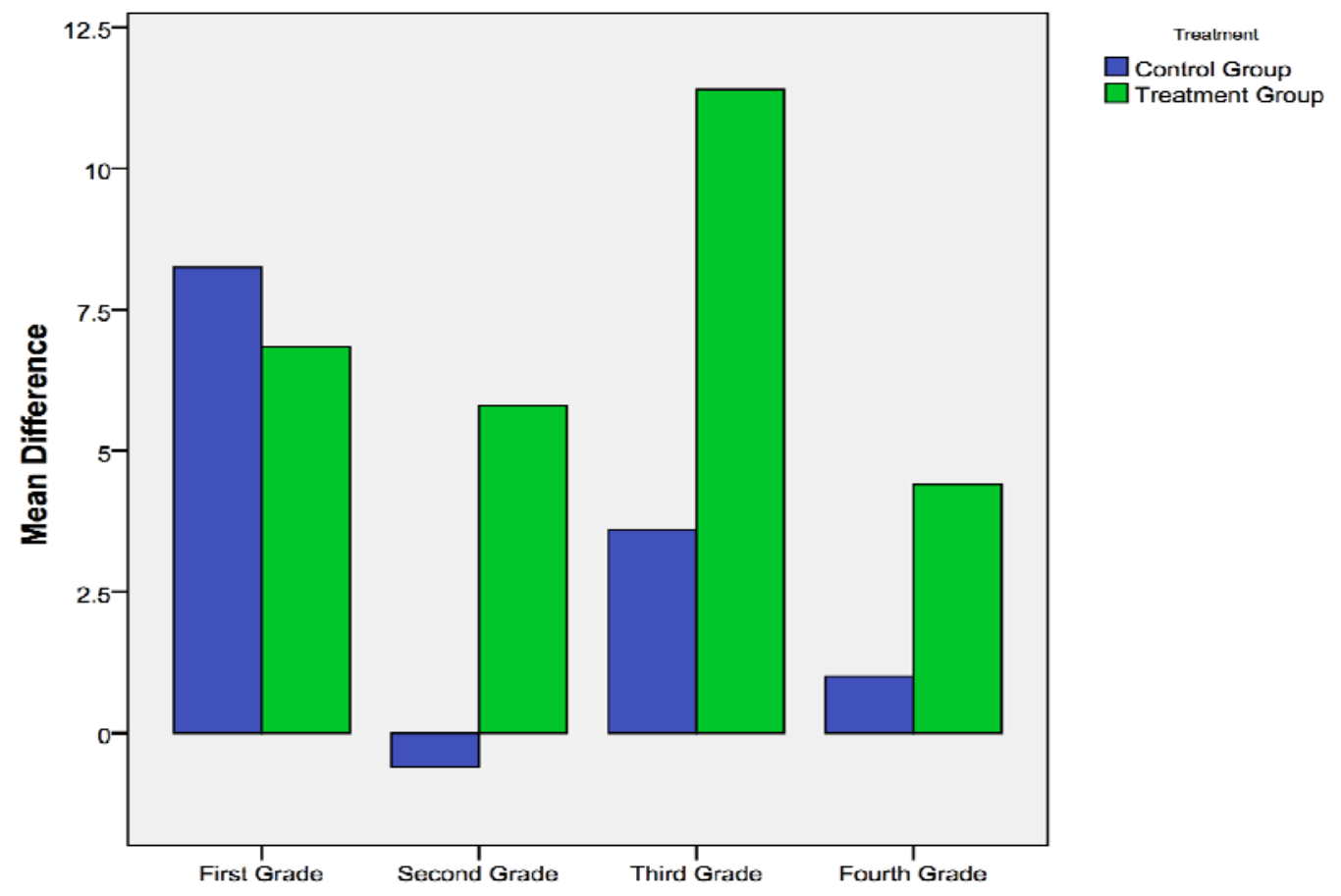

Figure 1: Average of Gains by Grade Level

Boys in the treatment group gained an average of 8.25 words while boys in the control group gained 3.91 words. Girls in the treatment group gained 5.56 words while girls in the control group gained 1.29 words. Once again, the results were analyzed using the repeated measures ANOVA and did not show that the difference between the control group and the treatment group was statistically significant $(p=.155)$. Figure 2 below visually shows the average gains of the control and the treatment group by gender 


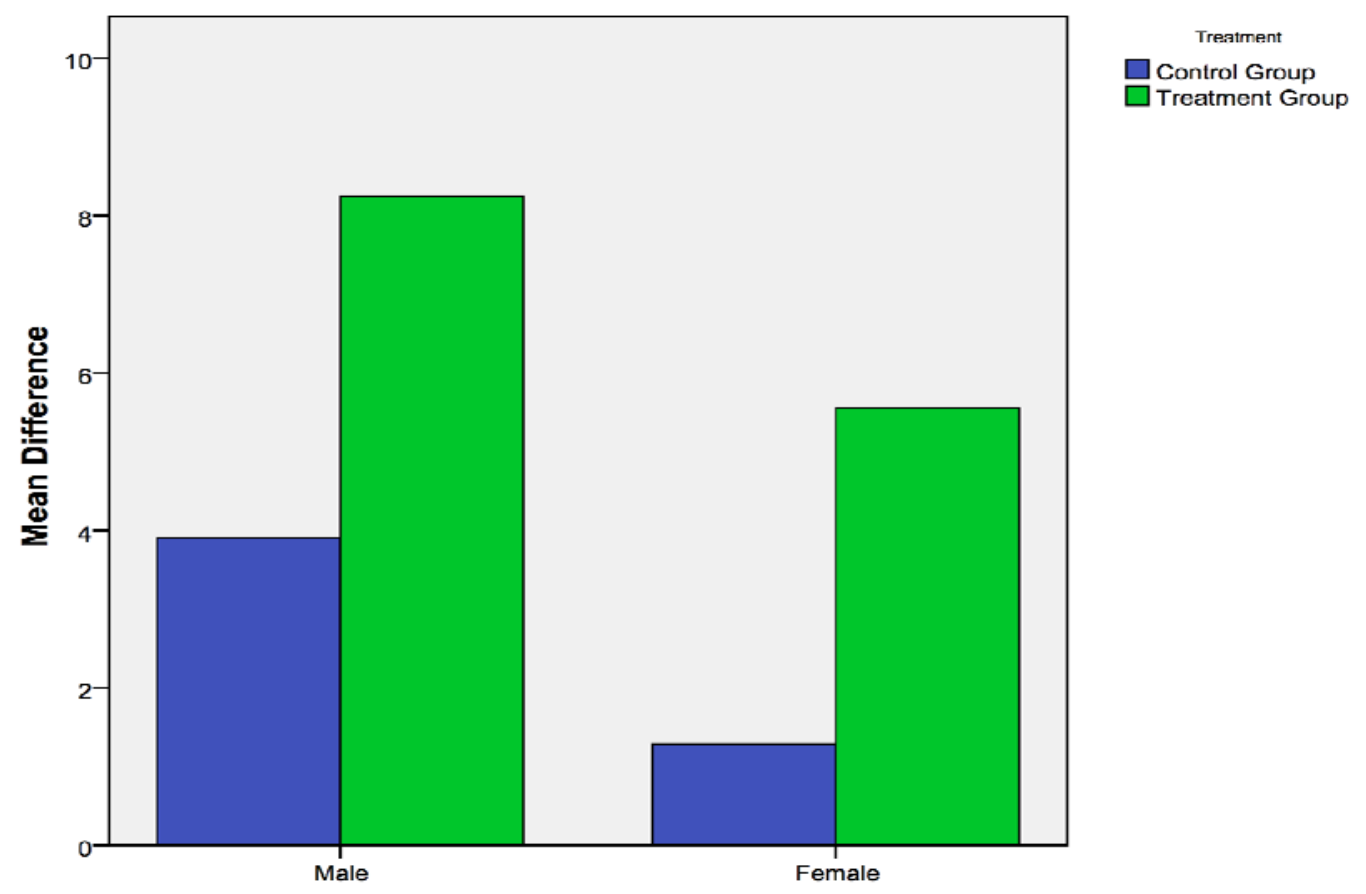

Figure 2: Average of Gains by Gender

While both the control group and the treatment group showed statistically significant gains between the pre-test and the post-test, there was no statistical difference between the control group and the treatment group. First grade students in the control group showed greater gains than students in the treatment group. Second, third, and fourth grade students in the treatment group showed greater gains than students in the control group. Both girls and boys in the treatment group gained more words than the students in the control group, despite the fact that boys scored higher than girls in both the pre-test and the post-test.

\section{Results to Research Question 2}

The secondary question of this study explored the perceptions and feelings of the students and teachers towards the Phonics Dance throughout the treatment process. The field notes that were taken were analyzed for themes and I found several overall themes 
that came up multiple times throughout the treatment. The first themes I will discuss deal with the perceptions of the students involved with the treatment. Following that, the observations made through conversations with the teachers will be discussed.

\section{Observations of Student Perceptions}

Theme 1

Students who had had previous experience with the Phonics Dance were more likely to be resistant to the use of the Phonics Dance. Students whose teachers had used the Phonics Dance for primary instruction prior to the treatment seemed to associate the Phonics Dance with kindergarten age activities. Despite the more difficult sounds and skills being taught during its use as an intervention tool, some students communicated that they felt it was something that they did when they were younger. Comments such as “I’ve already done this before like a million times" and "this is for kindergarteners" were made.

\section{Theme 2}

Students' reactions did not seem to differ due to grade level. While some students resisted the movements of the Phonics Dance, negative feelings towards the Phonics Dance were not communicated more or less frequently depending on the grade level of the students. Despite the intended age group of first to second grade, the fourth graders seemed to enjoy and learn from the program the same as the younger students.

\section{Theme 3}

Students’ initial reactions to the Phonics Dance differed by gender. As a whole, girls seemed to enjoy the Phonics Dance more initially than some boys. While many boys enjoyed the Phonics Dance, others made a joke of the motions or were reluctant to 
participate. A few boys made some negative comments including "this is boring" and "I hate dancing”. These comments were made toward the beginning of the treatment. Further into the treatment, the two boys who made the previous comments stated that "the dances are silly, but kind of fun" and told me that he "got to show (a couple other students) the ch- dance at recess”. Despite the initial resistance that many boys showed toward the Phonics Dance, by the end of the treatment, the boys were more verbal and involved in the movements and motions. Only two boys remained reluctant to participate in the treatment or demonstrated negative feelings towards the program at the end of the study.

None of the girls in the study expressed any negative views or feelings towards the program. To the contrary, many girls described the Phonics Dance as "super fun" and "this is fun, I wish we could stay longer.” While all the girls expressed only positive comments towards the program, some of the girls remained reserved and self-conscious as they performed the chants and motions to the dances.

Theme 4

Students' enjoyment of the Phonics Dance differed depending on the chant and movements. Dances that had more movements and were more song-like than chant-like were preferred while dances that had short, stilted movements and chant-like words were less favored. Many students expressed an appreciation for some dances over others with comments such as, "Yes! This is my favorite one!” and “I don’t like this one”. 


\section{Observations of Teacher's Perceptions}

Theme 1

Teachers who had not used the Phonics Dance before were interested in the use of the Phonics Dance. Out of the four teachers whose students participated in the Phonics Dance, two of the teachers had used or were familiar with the Phonics Dance. The two teachers that were unfamiliar with the Phonics Dance were intrigued when they noticed that many of their students were excited to go back and show other students what they had learned. One expressed interest in utilizing the Phonics Dance the following year and one was interested, but uneasy about learning the program.

\section{Theme 2}

The teachers did not notice any changes in behavior upon the students return to the general education classroom. I was interested to see if the students were more or less rambunctious following their participation in the Phonics Dance due to the more active aspects of the program. No teachers mentioned any increase or decrease in disruptive behaviors following the treatment, nor did they communicate a change in students' attitude towards their work. Two of the teachers did mention hearing the students comment on particular sounds during independent reading time or saying the chants to themselves as they sounded out words.

\section{Summary}

Despite the fact that the results showed that the students in the treatment group gained an average of 4.21 more words than students in the control group, no statistically significant difference was found. There was also no statistical difference found between 
the control group and the treatment group for the specific grade level being taught or for specific genders.

The students seemed to look favorably on the Phonics Dance program, even though some were resistant when initially introduced to the program. As a rule, students who had had previous experience with the program were more hesitant to enjoy the program, as were the male students regardless of grade level. Students also felt that some of the chants and dances were better and that impacted their perception of the program.

The teachers were interested in the use of the program and had only positive comments to share. They did not notice any changes in student behavior when students returned to their general education classroom. However, some teachers did notice their students utilizing the chants as they sounded out words during reading. 


\section{CHAPTER 5: CONCLUSION}

Applications of the Findings

The primary purpose of this study was to determine if the Phonics Dance is an effective intervention tool and whether or not it is more effective than a whole language approach. While this study did not demonstrate that the Phonics Dance is statistically more effective than the whole-language approach that was taken by the control group, there were several positive outcomes to using the Phonics Dance as an intervention tool that would make its use a beneficial option for intervention teachers of general education teachers who have students who are struggling in their ability to decode words.

The results did find that all students receiving intervention showed statistically significant gains in their ability to decode phonetically correct words, showing that targeting specific sounds is an effective strategy, even for older students.

The results showed that the Phonics Dance was most effective for students in second and third grade. This shows that the continuation of the Phonics Dance past the intended first grade and through second and third grade might be effective for students who are still struggling with basic decoding skills. Implementation of the Phonics Dance in these grades may increase students’ ability to decode words as well as provide multisensory instruction for students who have not been successful in reading with traditional methods.

Overall, students seemed to enjoy the Phonics Dance instruction and were actively engaged during instruction. I was concerned that the third and fourth grade students 
would have a negative opinion of the program and would not enjoy the motions and chants and feel that the program was too juvenile for them. However, their positive reaction to the program along with students' gains between the pre-test and post-test show that this is an effective method of instruction for the older age group.

Strengths of the Study

The primary strength of the study is that it confirms the findings of previous studies that show that the Phonics Dance is effective in improving students' decoding skills. Another strength of the study was that all students in the school that met the grade and reading level requirements were included in this study. Because of this, the internal validity of the study was very strong. Adding to the internal validity was the use of an identical pre-test and post-test and the control group.

Limitations of the Study

There were two major limitations to this study. The first limitation was the small sample size included in the study. This did not allow for a strong statistical basis to determine significance. The small sample size also makes it difficult to generalize the results to a larger population.

The second limitation of this study was the limited time frame of the intervention. If possible, a second post-test given the following school year would have strengthened the study and provided more information regarding the long-term effects of the Phonics Dance on students' decoding skills. A study on the retention of the skills learned during the treatment may have shown if the Phonics Dance was more effective with regard to maintenance and generalization of phonics skills. 


\section{Suggestions for Further Research}

Though the study did not show a statistically significant improvement, the Phonics Dance was demonstrated to be a promising intervention for students who are not adequately achieving through traditional teaching methods because all participating students improved their decoding skills through the intervention. In order to determine whether or not this intervention would become statistically significant and could be recommended as a reading intervention, additional research would be required. The following suggestions would improve and expand the findings of this study. First, this study had a small sample size, which hindered the results and outcomes from being generalized to other schools and populations. I would recommend similar studies to be completed with a larger sample size. I would also recommend similar studies to be done in schools with more diverse demographics. While all the students in the target school that met the grade level and reading ability requirements were included in the current study, it was still a small group and cannot be generalized to the general elementary school population without further studies. I also think that the small sample size affected the significance of the results and feel it would be beneficial to see a similar study conducted with a larger sample size of at least fifty students in each the control and the treatment group.

Another recommendation for further research would be to study the long term effects of the Phonics Dance on students’ ability to decode words. Since long-term benefits are the goal of reading interventions, it would be advantageous to see if is this particular method will be more or less effective in helping students retain the ability to

decode and attack new words. Doing so would assess not only if the Phonics Dance is an 
effective tool for instruction, but also if the motions and chants help students retain their grasp of phonics over an extended period of time.

The last recommendation would be to expand the study and measure growth in decoding skills as well as reading fluency over the course of several years to see if implementing the Phonics Dance over the course of a students' elementary education leads to more significant decoding and fluency improvements than traditional instruction. The ultimate goal of the Phonics Dance is to create a foundation of skills that allows students to read fluently and have the skills to decode unknown words so that they can access all texts. The current study dealt only with a few targeted sounds over a short period of time and did not test for gains students might make in fluency.

\section{Conclusion}

In conclusion, this study sought to determine if the Phonics Dance was an effective method for reading intervention for "at-risk" students in grades first through fourth grades. The study was conducted over the course of six weeks. The first week was used to assess students decoding skills prior to treatment. There were four weeks of treatment, during which time the students in both the control group and the treatment group learned eight new digraphs. The sixth week was spent assessing students’ decoding skills following the treatment. Evidence showed that students in both groups showed significant improvement in their ability to decode words. On average, students in the treatment group showed larger gains than students in the control group, with the exception of first grade, however none of the experimental groups showed a statistically significant improvement over the control groups. Some students who had had previous exposure to the program had a negative response to the implementation of the Phonics 
Dance as an intervention tool, however, the majority of students and teachers had a positive response to the program in general. Students were excited and engaged during instruction and teachers noticed that students were using the motions and chants while decoding words in the general classroom. While this study did not demonstrate a statistically significant difference between interventions using the Phonics Dance and a whole language approach, the results suggest that Phonics Dance may be a promising approach with which to address the learning needs of students who are not achieving success using traditional reading approaches. Additional, extended research would be necessary to determine whether or not the Phonics Dance is more successful than other intervention approaches. 


\section{REFERENCES}

Armstrong, T. (2000). Multiple intelligences. Alexandria, Virginia: Association for Supervision and Curriculum Development.

Boertje, M. W. (2009). The effectiveness of the phonics dance on reading fluency. (Unpublished Master of Education). University of Dayton.

Bostelman, T. J. (2008). The effects of rhyme and music on the acquisition of early phonological and phonemic awareness skills. (Unpublished Master of Education). Defiance College.

Bukowiecki, E. M. (2007). Teaching children how to READ. Kappa Delta Pi Record, 43(2), 58-65.

Campbell, M. L., Helf, S., \& Cooke, N. L. (2008). Effects of adding multisensory components to a supplemental reading program on the decoding skills of treatment resisters. Education and Treatment of Children, 31(3), 267-295.

Cihon, T. M., Gardner, R., Morrison, D., \& Paul, P. V. (2008). Using visual phonics as a strategic intervention to increase literacy behaviors for kindergarten participants at-risk for reading failure. Journal of Early and Intensive Behavior Intervention, 5(3), 138-155.

Committee on the Prevention of Reading Difficulties in Young Children. (1998).

Catherine E. Snow, M. Susan Burns and Peg Griffin (Eds.), Preventing reading difficulties in young children. Washington, D.C.: National Academy Press. 
Cunningham, P. M., \& Hall, D. P. (1998). Month-by-month phonics for upper grades : A second chance for struggling readers and students learning english. Greensboro, North Carolina: Carson-Dellosa Publishing Company, Inc.

Dowd, G. (1999). The phonics dance. Self-Published Manuscript.

Ediger, M. (2010). Pedagogic consistency: Philosophical perspectives in reading instruction. Virginia English Bulletin, 60(1), 14-19.

Ehri, L. C., Nunes, S. R., Stahl, S. A., \& Willows, D. M. (2001). Systematic phonics instruction helps students learn to read: Evidence from the National Reading Panel’s meta-analysis. Review of Educational Research, 71(3), 393-447.

Foy, J. G. and Mann, V. (2006) Changes in letter sound knowledge are associated with the development of phonological awareness in preschool children. Journal of Research in Reading, 29, 143-161.

Gipe, J. P. (2002). Multiple paths to literacy: Classroom techniques for struggling readers (5th ed.). Upper Saddle River, New Jersey: Pearson Education, Inc.

Heilman, A. W. (1976). Phonics in proper perspective. Columbus, Ohio: Bell \& Howell Company.

Henry, M. K. (2003). Unlocking literacy. Baltimore, Maryland: Paul H. Brookes Publishing Co.

Lambardo, M. A. (2005). Rhythmic reading and role playing. Library Media Connection, 38-39.

Longmire, A. C. (2008). Teacher perceptions regarding the use and effectiveness of the phonics dance with kindergarten through grade three students. (Unpublished Master of Education). Urbana University. 
Minskoff, E. (2005). Teaching reading to struggling learners. Baltimore, Maryland: Paul H. Brookes Publishing Co.

National Center for Education Statistics (2009). The Nation's Report Card: Reading 2009 (NCES 2010-458). Institute of Education Sciences, U.S. Department of Education, Washington, D.C.

National Institute of Child Health and Human Development. (2000). Report of the National Reading Panel. Teaching children to read: an evidence-based assessment of the scientific research literature on reading and its implications for reading instruction: Reports of the subgroups (NIH Publication No. 00-4754). Washington, DC: U.S. Government Printing Office.

Neuman, S.B. (2004) Hear, hear! Scholastic Parent and Child, 22.

Pinnell, G. S., Pikulski, J. J., Wixson, K. K., Campbell, J. R., Gough, P. B., \& and Beatty, A. S. (1995). Listening to children read aloud. Washington, DC. National Center for Education Statistics.

Pinnell, G. S., \& Fountas, I. C. (2009). When readers struggle: Teaching that works. Portsmouth, New Hampshire: Heinemann.

Rule, A. C., Dockstader, C. J., \& Stewart, R. A. (2006). Hands-on and kinesthetic activities for teaching phonological awareness. Early Childhood Education Journal, 34(3), 195-201.

Stanovich, K.E. (1986). Matthew Effects in Reading: Some Consequences of Individual Differences in the Acquisition of Literacy. Reading Research Quarterly, 21(4), 360-407.

The phonics dance. Retrieved 3/2, 2011, from http://www.phonicsdance.com 
U.S. Department of Education, National Center for Education Statistics. (2006). The Condition of Education 2006 (NCES 2006-071), Special Analysis.

Willis, J. (2007). Brain-friendly strategies for inclusion in the classroom. Alexandria, Virginia: Association for Supervision and Curriculum Development. 


\begin{abstract}
APPENDIX A
Sample Test Answer Sheet for First/ Second Grade
\end{abstract}

Pre-Test/ Post-test

$1^{\text {st }}$ and $2^{\text {nd }}$ Grade Answer Sheet

Directions to be read to student: This is to see how well you can read some sounds. Read the words out loud as best as you can. If you are not sure, do your best and move to the next word. The first words are made-up words. Sound them out to read them.

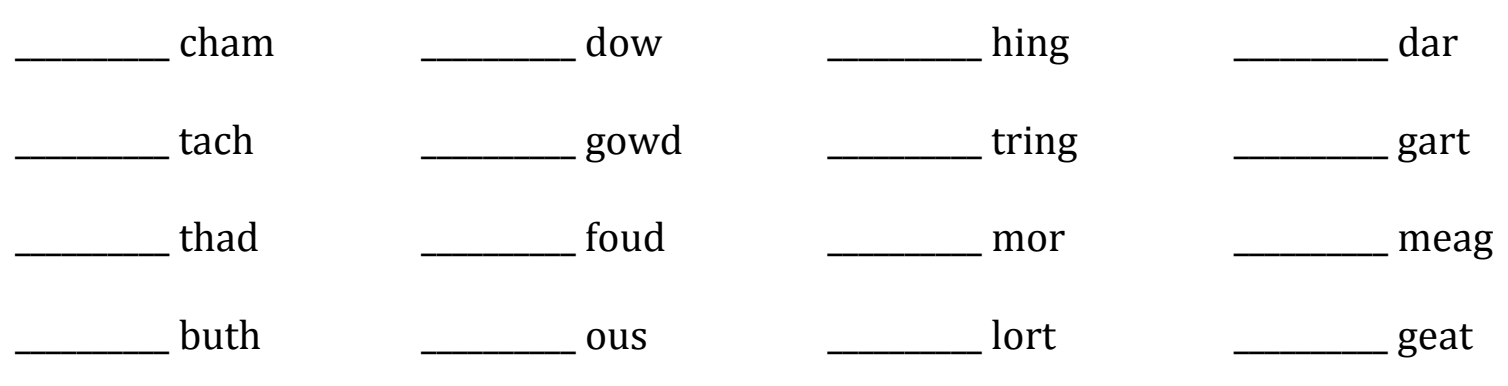

Read to student: Good Job! Now I want you to read some words that you might recognize. Remember to sound the words out if you need to.

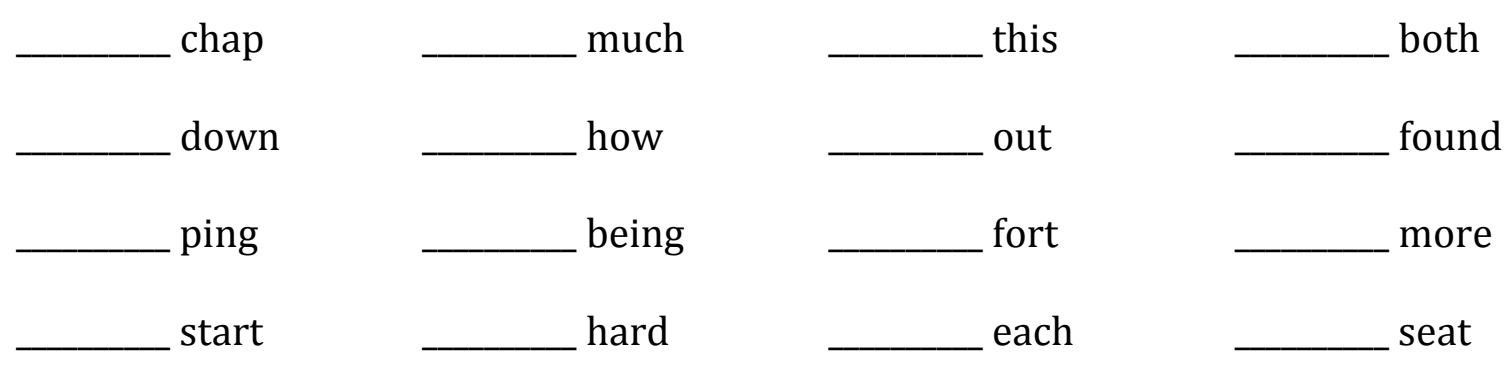

Read to student: Great! Now I would like you to read the paragraph as best as you can. If you get stuck on a word, don't worry. Just skip it and keep going.

We went to the park for a picnic outside. When we got there, we had to eat first. Then I played on the swings. Next, I went down the slide. I had so much fun! 
APPENDIX B

Sample Test for First/ Second Grade

$$
\begin{gathered}
\text { Pre-Test/ Post-test } \\
1 \text { st and } 2^{\text {nd }} \text { Grade Student Copy }
\end{gathered}
$$

$\begin{array}{llcl}\text { cham } & \text { dow } & \text { hing } & \text { dar } \\ \text { tach } & \text { gowd } & \text { tring } & \text { gart } \\ \text { thad } & \text { foud } & \text { mor } & \text { meag } \\ \text { buth } & \text { ous } & \text { lort } & \text { geat }\end{array}$

$\begin{array}{llll}\text { chap } & \text { much } & \text { this } & \text { both } \\ \text { down } & \text { how } & \text { out } & \text { found } \\ \text { ping } & \text { being } & \text { fort } & \text { more } \\ \text { start } & \text { hard } & \text { each } & \text { seat }\end{array}$

We went to the park for a picnic outside. When we got there, we had to eat first. Then I played on the swings. Next, I went down the slide. I had so much fun! 


\begin{abstract}
APPENDIX C
Sample Test Answer Sheet for Third/Fourth Grade
\end{abstract}

\author{
Pre-Test/ Post-test \\ $3^{\text {rd }}$ and $4^{\text {th }}$ Grade Answer Sheet
}

Directions to be read to student: This is to see how well you can read some sounds. Read the words out loud as best as you can. If you are not sure, do your best and move to the next word. The first words are made-up words. Sound them out to read them.

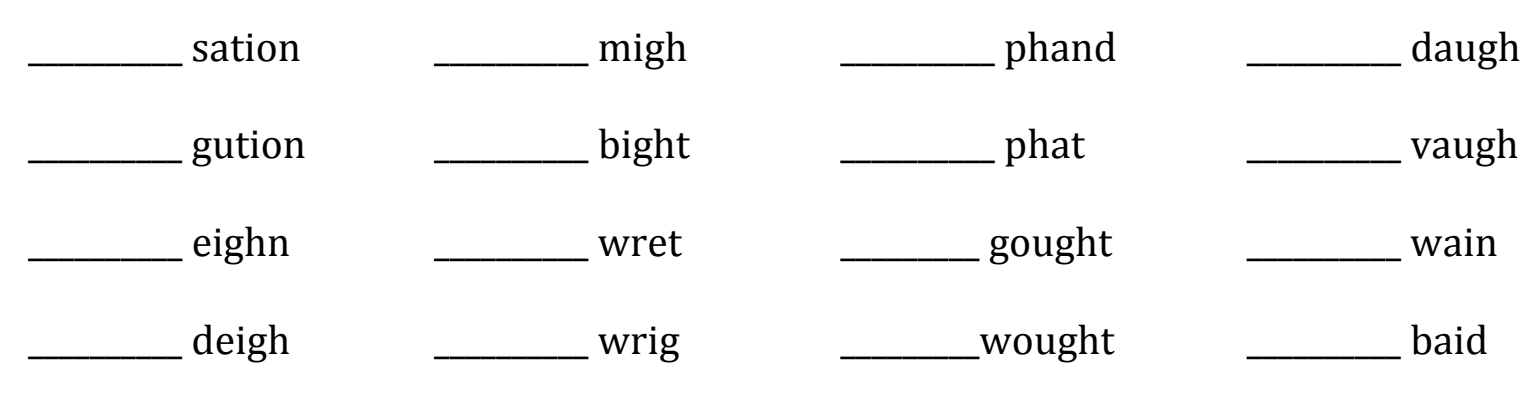

Read to student: Good Job! Now I want you to read some words that you might recognize. Remember to sound the words out if you need to.

\begin{tabular}{|c|c|c|c|}
\hline action & bright & __ phone & daughter \\
\hline nation & night & elephant & _taught \\
\hline _ eight & write & thought & _ gain \\
\hline eighbor & wrong & _bought & rain \\
\hline
\end{tabular}

Read to student: Great! Now I would like you to read the paragraph as best as you can. If you get stuck on a word, don't worry. Just skip it and keep going.

I called my friend at eight o'clock last night. I had a question about our school project. We had to write a report about elephants. Our teacher had taught us all about them and I thought that we should get started. The main part was a written report, but we also had to make a poster. This was going to be a great project. 


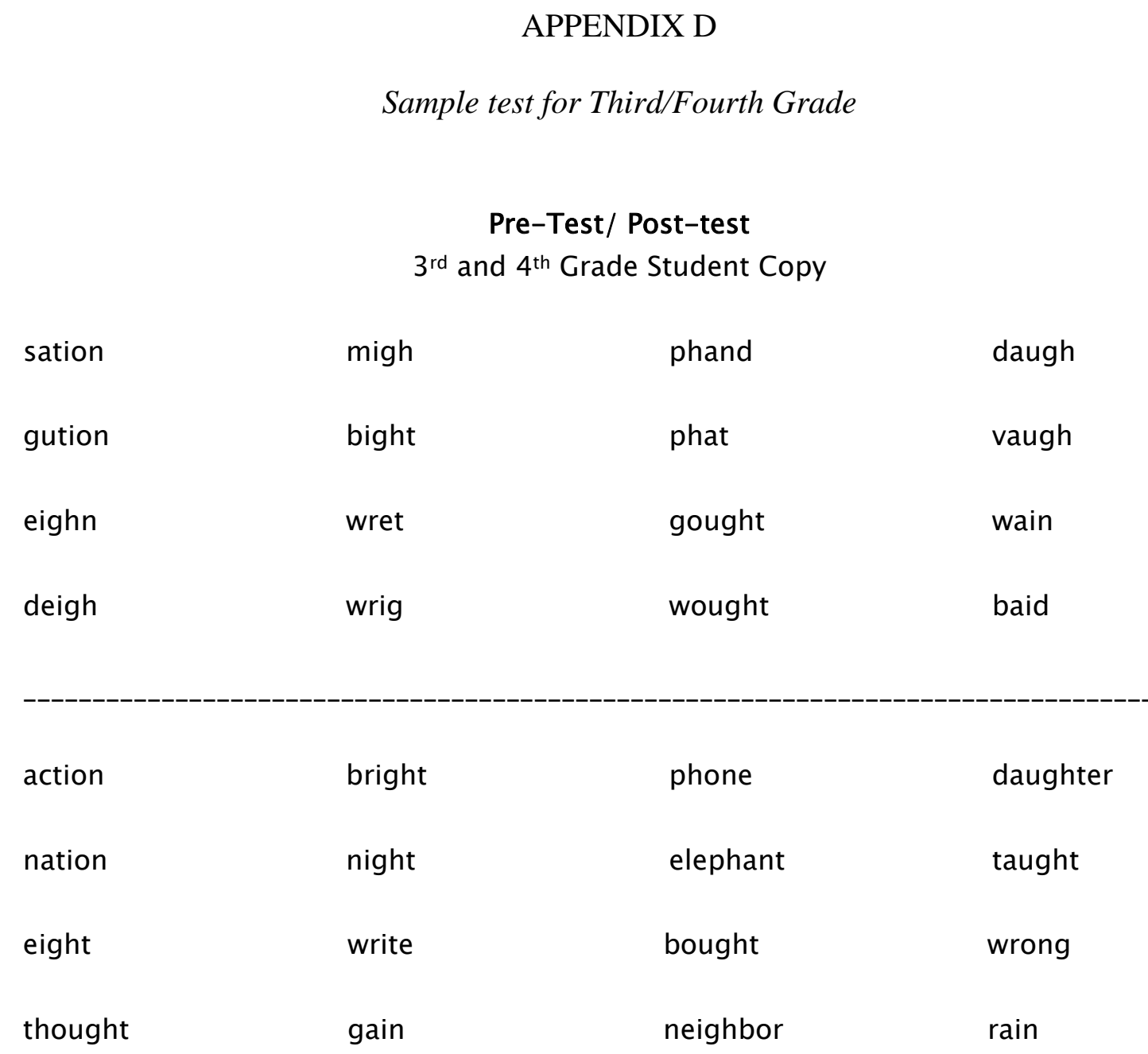

I called my friend at eight o'clock last night. I had a question about our school project.

We had to write a report about elephants. Our teacher had taught us all about them and I thought that we should get started. The main part was a written report, but we also had to make a poster. This was going to be a great project. 
